\title{
An investigation of screening for medical referral by Physical Therapists
}

\author{
Heather E. Mount \\ Alabama State University, hmount@faulkner.edu \\ Cecilia Graham \\ University of Alabama at Birmingham, cgraham@uab.edu \\ Diane Clark \\ University of Alabama at Birmingham \\ David Morris \\ University of Alabama at Birmingham \\ Kathleen Foley \\ Brenau University
}

Follow this and additional works at: https://nsuworks.nova.edu/ijahsp

Part of the Physical Therapy Commons, and the Physiotherapy Commons

\section{Recommended Citation \\ Mount HE, Graham C, Clark D, Morris D, Foley K. An investigation of screening for medical referral by Physical Therapists. The Internet Journal of Allied Health Sciences and Practice. 2016 Jan 01;14(2), Article 2.}

This Manuscript is brought to you for free and open access by the College of Health Care Sciences at NSUWorks. It has been accepted for inclusion in Internet Journal of Allied Health Sciences and Practice by an authorized editor of NSUWorks. For more information, please contact nsuworks@nova.edu. 


\title{
An investigation of screening for medical referral by Physical Therapists
}

\begin{abstract}
Screening for medical referral is essential to physical therapist practice; however, no studies have examined medical screening across physical therapy practice settings. The purpose of this study was to determine if physical therapists in a variety of practice settings, given brief clinical vignettes, would screen for medical referral in a similar manner. The Delphi Technique was implemented to establish content validity, although only 2 vignettes reached $100 \%$ consensus by the expert panel. After reviewing the vignettes, physical therapist subjects determined if they would provide intervention, provide intervention and refer, or refer before intervention. To determine which variables were associated with identified appropriate decisions in each category, 4 sets of logistic regressions were performed. A random sample of APTA members in targeted sections $(n=214)$ completed the survey. Physical therapists with more than 23 years experience were 7 times more likely to make similar management decisions in noncritical vignettes then those with 11 years or less. Half of the participants practiced in outpatient practice settings. In critical medical vignettes, $86 \%$ of physical therapists made similar decisions. Physical therapists in this study made identified appropriate management decisions for $90 \%$ of the vignettes. Board certification, practice setting and highest earned degree were not found to be statistically significant. It is imperative not only to ensure that the client is appropriate for physical therapy intervention, but it is also vital to recognize and identify signs and symptoms that warrant evaluation by other health care providers.
\end{abstract}

\section{Author Bio(s)}

Heather E. Mount, PT, DSc, OCS, cert MDT is an associate professor in the College of Health Sciences at Alabama State University in Montgomery, Alabama. She is also a licensed Physical Therapist in the state of Alabama.

Dr. Cecilia Graham was Associate Professor and Director of the Doctor of Science in Physical Therapy Program in the Department of Physical Therapy at The University of Alabama at Birmingham at the time this study was conducted.

Dr. Diane Clark, PT, DSc, MBA is the Program Director and Associate Professor in the School of Health Professions at the University of Alabama Birmingham. She is also a licensed Physical Therapist.

Dr. Davis Morris is the Interim Chair of the Department of Physical Therapy Program and Professor in the School of Health Professions at the University of Alabama Birmingham. He is also a licensed Physical Therapist.

Dr. Kathleen Foley, PhD, OTR/L is Associate Professor and Research Coordinator at the North Atlanta Campus at Brenau University as well as a licensed Occupational Therapist. 


\title{
IUAHSP \\ The Internet Joưnal of Allied Health Sciences and Practice \\ Dedicated to allied health professional practice and education
}

Vol. 14 No. 2 ISSN 1540-580X

\section{An Investigation of Screening for Medical Referral by Physical Therapists}

\author{
Cecilia Graham, $\mathrm{PhD}, \mathrm{PT}^{2}$ \\ Diane Clark, PT, DSc, MBA² \\ David Morris, $\mathrm{PhD}, \mathrm{PT}^{2}$ \\ Kathleen Foley, PhD, OTR ${ }^{3}$ \\ 1. Alabama State University \\ 2. University of Alabama \\ 3. Brenau University \\ United States
}

Heather E. Mount, PT, DSc, OCS, cert MDT1

\begin{abstract}
Screening for medical referral is essential to physical therapist practice; however, no studies have examined medical screening across physical therapy practice settings. The purpose of this study was to determine if physical therapists in a variety of practice settings, given brief clinical vignettes, would screen for medical referral in a similar manner. The Delphi Technique was implemented to establish content validity, although only 2 vignettes reached $100 \%$ consensus by the expert panel. After reviewing the vignettes, physical therapist subjects determined if they would provide intervention, provide intervention and refer, or refer before intervention. To determine which variables were associated with identified appropriate decisions in each category, 4 sets of logistic regressions were performed. A random sample of APTA members in targeted sections $(n=214)$ completed the survey. Physical therapists with more than 23 years experience were 7 times more likely to make similar management decisions in noncritical vignettes then those with 11 years or less. Half of the participants practiced in outpatient practice settings. In critical medical vignettes, $86 \%$ of physical therapists made similar decisions. Physical therapists in this study made identified appropriate management decisions for $90 \%$ of the vignettes. Board certification, practice setting and highest earned degree were not found to be statistically significant. It is imperative not only to ensure that the client is appropriate for physical therapy intervention, but it is also vital to recognize and identify signs and symptoms that warrant evaluation by other health care providers.
\end{abstract}

\section{INTRODUCTION}

Screening for medical referral (SMR) is the process by which physical therapists determine whether a patient/client is appropriate for physical therapy intervention. It involves the collection of relevant data, including past medical and family history, risk factor assessment, clinical presentation, associated signs and symptoms, and review of systems. ${ }^{1}$ Differentiating between mechanical dysfunction and pathologic conditions can be extremely difficult. A thorough screening determines if the patient presents with a condition that falls within the scope of practice and identifies any red or yellow flags, risk factors, or clusters of symptoms that may suggest a systemic problem. ${ }^{2}$ The result of this process could be referral or consultation with another medical professional, such as a physician.

The American Physical Therapy Association (APTA) recognizes the importance of SMR to the safe and effective practice of physical therapy. The Guide to Physical Therapist Practice states, "Physical therapists also must determine whether referral to or consultation with another provider is indicated based on the information gathered during the initial encounter with the individual and during subsequent interactions." ${ }^{3}$ The transition to the entry-level doctorate has facilitated the increased focus on SMR in educational programs. The Commission on Accreditation in Physical Therapy Education requires all entry-level physical therapy programs to include screening for medical referral. ${ }^{4}$ The World Confederation of Physical Therapy also acknowledges the 
importance of SMR. "When the diagnosis is not clear or the required intervention/treatment is not within the realm of physical

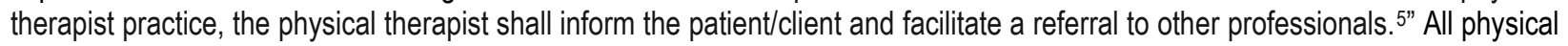
therapists are responsible for the safety, appropriate treatment, and referral of individuals in their care. ${ }^{6}$

SMR is vital to physical therapist practice in all settings. Patients often have complex and progressive histories with signs and symptoms that require a thorough screening to ensure physical therapy intervention is appropriate. Technological advances have decreased recovery time for many medical conditions, decreased hospital stays, and decreased the mortality rate. People are living longer and often doing so with two or more chronic illnesses or disabilities. ${ }^{1}$ Conditions can change over time or progress quickly. Typical signs and symptoms of many disorders, such as cancer ${ }^{1}$ may not be present or can mimic conditions physical therapists regularly treat. SMR may involve signs and symptoms other than the chief complaint. In a review of 78 published case studies of SMR, $16.7 \%$ ( $n=13$ ) of the referrals were unrelated to the primary concern. ${ }^{7}$ Accurate diagnosis and early detection of pathologic conditions is important to prevent or minimize complications and co-morbidities. ${ }^{2}$

Physical therapy is becoming a first point of entry into the health care system. All 50 states allow some form of direct access, and an increasing number of physical therapists are practicing in primary care environments. ${ }^{2}$ In a 2010 survey by the APTA, $55 \%$ of members who responded reported that they provide direct access services. Although the majority of those participants practiced in hospital based outpatient and private practice settings, direct access care was provided by physical therapists in all settings. ${ }^{8}$ Physical therapists in the United States Army have been successfully practicing in a primary care role since the 1970s. SMR is an essential component of their practice. More recently, Kaiser Permanente Northern California implemented a similar model of practice that includes SMR. ${ }^{9}$

While it is unclear how often physical therapists are referring patients to other health care professionals, a 2012 article highlights the significance of this process and suggests a need for further research related to SMR. ${ }^{7}$ The article identified 78 published case reports describing SMR by physical therapists to physicians that resulted in a medical diagnosis. Only 20 of the 78 patients were seen through direct access. The remaining 58 patients were referred to physical therapy by their physician; however; no conclusions on SMR by physical therapists can be drawn based on these findings. ${ }^{7}$ The research thus far has not consistently demonstrated the ability or consistency of physical therapists to perform SMR.

One study suggests that physical therapists can recognize conditions that necessitate a referral. A 2005 study found that experienced physical therapists had higher levels of knowledge in managing musculoskeletal conditions than all physician specialists except orthopedists. ${ }^{10}$ Some of the conditions included fractures and dislocations as well as emergent situations such as compartment syndrome. This study involved physical therapists practicing in the military as physician extenders.

The majority of research has been unsatisfactory. A 2004 study examined physical therapists ability to screen for depression in low back pain in outpatient clinics. ${ }^{11}$ Compared to a reference standard, the Depression Anxiety Stress Scale, physical therapists were not as accurate in diagnosing depression, even severe depression. Physical therapists also had difficulty determining the probability of deep vein thrombosis (DVT) using the Wells Clinical Prediction Rule. ${ }^{12}$ Participants sampled from the APTA's private practice section were given 6 hypothetical vignettes and determined if they would contact a physician. For the 2 vignettes that were deemed moderate probability for DVT, $15 \%$ and $30 \%$ of participants would not have contacted the physician. Given the 2 vignettes that presented with a high probability of DVT, $32 \%$ and $27 \%$ of participants would not have contacted the physician. The participants underestimated the probability of DVT in the high probability vignettes by more than $60 \%$. Board certification, practice setting or region of the country did not impact the results. ${ }^{12}$

Vignettes have been utilized to examine physical therapists' ability to accurately screen for medical referral. ${ }^{13}$ Vignettes were developed and reviewed by an expert panel. The vignettes were distributed to a random sample of members of the APTA's private practice section. For each vignette, respondents were asked to determine whether they would proceed with the intervention, provide the intervention and also consult or refer with another medical professional, or refer to another medical professional prior to intervention. An expert panel determined the correct management decision. Approximately $50 \%$ of the participants made the correct management decision in all vignettes. Participants made a correct decision for $87.3 \%$ of the vignettes when intervention was appropriate, $87.8 \%$ of the vignettes when providing intervention and then consulting or referring was indicated and $79.0 \%$ of the vignettes when the correct decision was to refer. The researchers examined years of experience, degree obtained, and specialist certification. Physical therapists with an orthopedic certification from the American Board of Physical Therapy Specialties (ABPTS) were almost twice as likely to make correct decisions in critical medical and musculoskeletal vignettes then participants that were not certified.

(C) The Internet Journal of Allied Health Sciences and Practice, 2016 
There have not been any studies that have examined the medical screening ability of physical therapists in practice settings outside of outpatient or private practice; however, screening for medical referral is necessary in all practice settings. Physical therapists must ensure the safety and appropriateness of intervention for the clients in their care. New graduates are expected to be able to practice in different practice settings. Many clinicians, such as those in rural areas or in primary care, may practice as generalists encountering a variety of conditions. Therefore, the purpose of this study was to determine if physical therapists, regardless of practice setting, could recognize situations in which a referral or consultation with a medical professional would be indicated. The study also examined the relationship between physical therapists' accuracy in screening for medical referral and years of experience, entry-level degree, highest degree obtained, and specialist certification.

\section{METHODS}

\section{Survey Development}

Institutional Review Board approval for the study was obtained from the University of Alabama at Birmingham (UAB). The survey contained 2 parts. The first part was the demographic component, which was adapted from the APTA demographic survey. The second component consisted of 12 vignettes, which were developed from a variety of resources. With permission, 3 of the vignettes were adapted from the study by Jette in 2006 and 4 vignettes were adapted from a graduate level course series in medical screening in the Doctor of Science in Physical Therapy program at UAB. ${ }^{13}$ The remainder of vignettes were designed to represent realistic patient scenarios that might be encountered in different practice settings using literature, textbooks, and clinical experience.1,2,14,15 Each vignette contained a brief medical history and description of signs and symptoms. Participants were asked to make a management decision based only on the information provided. Conditions that required a referral to another health care professional were considered critical or non-critical based on the urgency with which a referral was indicated.

\section{Vignettes}

The Delphi Technique was performed to establish the content validity of the vignettes. ${ }^{16}$ The technique involved experts anonymously replying to questionnaires and receiving feedback of the group response in order to achieve consensus. Three rounds of questionnaires were sent to a panel of experts to develop and reach consensus on various vignettes. The panel consisted of 9 members: 3 physical therapists considered experts in their field with at least 10 years of experience and continuing education in screening for medical referral, 3 physicians who also previously or currently practice as physical therapists, and 3 physical therapists that teach screening for medical referral in the academic setting. The demographic information of the expert panels is provided in Table 1.

In the first round, 12 vignettes were presented. Panel members responded to open- and closed-ended questions and were asked to make comments. They were also asked to make a management decision. Three choices were given based on the study by Jette in 2006: 1) Proceed with physical therapy intervention without medical referral (treat), 2) Provide physical therapy intervention and then consult with or refer to a medical professional (treat and then consult, or 3) Refer the patient to a medical professional before any physical therapy intervention (refer). ${ }^{13}$ One of the expert panel members dropped out of the study after round one. In the second round, the panel was able to make additional comments and suggestions as well as select the correct management decision. In the third round the panel was asked to select the correct management decision.

After each round, the management responses were totaled and comments reviewed. Appropriate revisions were made to the vignettes based on comments from the panel while keeping the vignettes brief. If a vignette achieved $100 \%$ consensus, the vignette was eliminated from further rounds. One vignette was eliminated during each of the first two rounds. All vignettes were included in the study if they reached a consensus of at least $75 \%$ after round 3 . At the completion of the Delphi study, 4 vignettes were eliminated from the study because they did not reach this threshold. The final 8 vignettes that resulted from the Delphi Technique are provided in the appendix. Only 2 vignettes reached 100\% consensus by the expert panel.

Table 1. Delphi Panel Characteristics

\begin{tabular}{|l|l|}
\hline $\begin{array}{l}\text { Highest Earned } \\
\text { Degree }\end{array}$ & $\mathrm{MD}(3)$, Doctor of Science (3), EdD (1), PhD (1), MS (1) \\
\hline $\begin{array}{l}\text { Average Years of } \\
\text { Experience }\end{array}$ & 20 \\
\hline Types of Certification & $\begin{array}{l}\text { Athletic Training, NCS, GCS, Mechanical Diagnosis and Therapy, Vestibular Rehabilitation, } \\
\text { CEEAA }\end{array}$ \\
\hline
\end{tabular}

@ The Internet Journal of Allied Health Sciences and Practice, 2016 


\section{Participants}

A random sample of 1,100 physical therapists was initially contacted. This was based on the total membership of targeted sections of the APTA, approximately 31,500 , a desired confidence interval of $+1-5 \%$, and an estimated response rate of $35 \%$. Specific sections were sampled to attempt to obtain participants in 4 target practice settings: acute care, outpatient/private practice, home health, and inpatient rehabilitation. Additional sampling was performed in several sections because of a low response rate in the targeted practice settings. The total number of physical therapists contacted in each section is listed in Table 2.

Physical therapists were contacted via email addresses obtained from the membership directory of the APTA website. The email explained that the purpose of the study was to examine the ability of physical therapists to screen for medical referral and included a link to the survey on QuestionPro. To ensure that respondents were regularly involved in patient care, physical therapists currently practicing at least 20 hours per week in one of the target practice settings were included in the study.

Participants were informed that the vignettes were intentionally brief in order to avoid being a burden to busy clinicians. The survey instructions acknowledged that in a clinical situation additional tests would likely be carried out prior to a final decision being made. Respondents were provided with the same 3 management decisions for each vignette as in previous studies. ${ }^{13}$

Table 2. Numbers of Subjects Contacted

\begin{tabular}{|l|c|c|}
\hline \multicolumn{1}{|c|}{ APTA Section } & Total Number Sampled & Approximate Total \\
\hline Orthopedic section & 122 & 12400 \\
\hline Sports section & 122 & 4500 \\
\hline Private practice section & 122 & 3200 \\
\hline Acute care section & 182 & 1800 \\
\hline $\begin{array}{l}\text { Cardiovascular and pulmonary } \\
\text { section }\end{array}$ & 122 & 700 \\
\hline Oncology section & 162 & 700 \\
\hline Geriatric section & 162 & 3700 \\
\hline Neurology section & 162 & 2700 \\
\hline Home health section & 222 & 1800 \\
\hline
\end{tabular}

\section{Data Analysis}

Data analysis was performed using IBM SPSS version 19, New York. Descriptive statistics were used to describe the characteristics of the participants as well as percentages of participants who made identified appropriate management decisions in each vignette. Based on the study by Jette in 2006, the management decision chosen by the expert panel was utilized to divide the vignettes into 3 categories..$^{13}$ If the management decision was to provide intervention without a referral, the vignette was considered a traditional vignette. If the decision was to proceed with the intervention then consult or refer, the vignette was a non-critical medical vignette. If the decision was to refer to another health care professional prior to physical therapy intervention, the vignette was deemed a critical medical vignette. Correct management decisions for traditional vignettes were to treat or to treat and then consult. An incorrect response was to refer before further treatment. Noncritical medical vignettes were considered correct if the participant chose to treat and then consult or to refer before further treatment. An incorrect response was to treat without consultation or referral. Critical medical vignettes were considered correct only if the participant chose to refer before further treatment.

For each category of vignettes, a mean percentage of correct decisions was calculated and participants were further classified based on whether they scored $100 \%$ on all vignettes or less than $100 \%$. To be considered for this analysis, a participant had to respond to all vignettes in that category. The difference in the frequency of correct decisions made by the participants across the three types of vignettes was tested using a chi-square statistic.

Four sets of binary logistic regressions were performed to determine which variables were associated with correct management decisions in each of the categories of vignettes. ${ }^{6}$ Odds ratios and the $95 \%$ confidence intervals related to scoring $100 \%$ on the relevant vignettes were determined for each level of the independent variables in those models that were significant. The independent variables included practice setting (inpatient, outpatient), years of experience ( $\leq 11$ years, $12-22$ years, $\geq 23$ years), certification (yes, no) and highest earned degree (baccalaureate, masters, doctorate, PhD). As a result of the small sample size, the setting variable was collapsed. The inpatient category included participants in acute care, inpatient rehabilitation, and longterm care facilities. The outpatient category included participants in home health, outpatient, private practice and health and 
wellness. Visual binning was performed to divide years of experience into 3 equal groups using the median as the cutoff point. Based on multicollinearity statistics and a Pearson bivariate correlation of 0.76 between years of experience and entry level degree, entry-level degree was eliminated from the regression analyses. ${ }^{6}$

\section{RESULTS}

Survey requests were sent to 1378 physical therapists. Sixteen requests were returned due to invalid email addresses. The survey was accessed by $391(29 \%)$ of the 1362 physical therapists contacted. Of the 391 that responded, $214(62 \%)$ met the inclusion criteria and completed the survey and $77(20 \%)$ exited the survey prior to completion. The 100 respondents $(26 \%)$ that did not meet the inclusion criteria were redirected to the exit page of the survey. With a sample size of 214, the margin of error was calculated to be $6.68 \%$.

The demographic characteristics of the participants are listed in Table 3. The age range of the participants was 25 to 69 years, with a mean age of 43.81 years $(S D \pm 10.9)$. For each vignette, the percentage of participants who chose the correct management response as well as the percent agreement of the identified appropriate management decision between members of the Delphi panel is found in Table 4. The chi square test of independence was performed and indicated a significant difference in correct responses across the three types of cases $\left(x^{2}=112.79, d f=2, p=0.001\right)$. The mean percent of correct responses for participants who completed all 8 vignettes, as well as for each category of vignettes is listed in Table 5 . The percentage of participants who made identified appropriate management decisions for each category of vignettes is also listed in Table 5. 
Table 3. Characteristics of Sample

\begin{tabular}{|c|c|c|c|}
\hline & Study Sample & & APTA Membershipb \\
\hline Characteristic & $\%$ & $n^{a}$ & $\%$ \\
\hline \multicolumn{4}{|l|}{ Gender } \\
\hline Male & 41.6 & 89 & 31.7 \\
\hline Female & 58.4 & 125 & 68.3 \\
\hline \multicolumn{4}{|l|}{ Region } \\
\hline Midwest & 27.3 & 57 & \\
\hline Northeast & 21.1 & 44 & \\
\hline Northwest & 14.4 & 30 & \\
\hline Southwest & 17.7 & 37 & \\
\hline Southeast & 19.6 & 41 & \\
\hline \multicolumn{4}{|l|}{ Years' Experience } \\
\hline$<=10 \mathrm{yrs}$ & 31.1 & 65 & 33.6 \\
\hline $11+\mathrm{yrs}$ & 68.9 & 144 & 66.4 \\
\hline \multicolumn{4}{|l|}{ Entry level Degree } \\
\hline Baccalaureate & 41 & 86 & 47.1 \\
\hline Masters/Post & 32.8 & 69 & 33.2 \\
\hline Doctorate & 24.3 & 51 & 17.3 \\
\hline Other & 4 & 1.9 & 2.1 \\
\hline \multicolumn{4}{|l|}{ Highest Degree } \\
\hline Baccalaureate & 22.3 & 47 & 24.7 \\
\hline Masters & 29.9 & 63 & 32.0 \\
\hline Entry Level Doctorate & 20.9 & 44 & 20.7 \\
\hline Transitional Doctorate & 18.0 & 38 & 13.8 \\
\hline PhD & 9.0 & 19 & 6.7 \\
\hline \multicolumn{4}{|l|}{ Certification } \\
\hline No & 76.1 & 162 & 99.9 \\
\hline Yes & 23.9 & 51 & $>0.00$ \\
\hline \multicolumn{4}{|l|}{ Practice Setting } \\
\hline Home Health & 14.6 & 31 & 6.8 \\
\hline Rehab Hospital & 4.2 & 9 & 8.1 \\
\hline Outpatient/Private Practice & 50.0 & 106 & 55.5 \\
\hline Acute Care & 20.8 & 44 & 11.4 \\
\hline SNF/ECF/ICF & 6.5 & 14 & 5.1 \\
\hline School & 0.9 & 2 & 3.6 \\
\hline Academia & 0.5 & 1 & 0.5 \\
\hline Health and Wellness & 0.5 & 1 & 0.5 \\
\hline Other & 1.9 & 4 & 4.7 \\
\hline
\end{tabular}

aThe number of participants represented by each variable may be different because of missing data. b Membership Statistics 2011

\begin{tabular}{|c|c|c|c|}
\multicolumn{4}{c}{ Table 4. Percentage of Participants Making Correct Management Decisions } \\
\hline Vignette & $\begin{array}{c}\text { \% of Participants Making Identified } \\
\text { Appropriate Management Decisions }\end{array}$ & $\begin{array}{c}\text { Delphi Study \% } \\
\text { Agreement }\end{array}$ \\
\hline 2 & 88.7 & 210 & $75 \%$ \\
\hline 5 & 91.8 & 207 & $75 \%$ \\
\hline 6 & 88.2 & 204 & $100 \%$ \\
\hline 7 & 96.0 & 200 & $100 \%$ \\
\hline 8 & 86.6 & 202 & $88 \%$ \\
\hline 9 & 93.5 & 201 & $75 \%$ \\
\hline 10 & 86.9 & 199 & $75 \%$ \\
\hline 11 & 93.4 & 196 & $75 \%$ \\
\hline
\end{tabular}

aThe number of participants represented in each vignette may be different because of missing data 
Only one logistic regression model was found to be statistically significant. The logistic regression model for non-critical medical vignettes containing the independent variable "years of experience" was statistically significant $\left(X^{2}=27.6 p=0.002\right)$. The likelihood of making correct decisions in $100 \%$ of vignettes was 7 times higher for participants with at least 23 years of experience when compared to those with 11 years or less $(\mathrm{OR}=7.09, \mathrm{Cl}=2.2-22.4)$. The model explained between $13.9 \%$ (Cox and Snell $\mathrm{R}$ square) and $19.6 \%$ (Nagelkerke R-squared) of the variance and correctly classified $68.6 \%$ of vignettes.

Table 5. Summary of Management Decisions by Category of Vignettes

\begin{tabular}{|c|c|c|c|c|}
\hline & $\begin{array}{c}\text { Traditional } \\
\mathrm{n}=201\end{array}$ & $\begin{array}{c}\text { NonCritical Medical } \\
\mathrm{n}=193\end{array}$ & $\begin{array}{c}\text { Critical Medical } \\
\mathrm{n}=200\end{array}$ & $\begin{array}{c}\text { Total } \\
\mathrm{n}=189\end{array}$ \\
\hline $\begin{array}{c}\text { Mean percent correct } \\
\text { answers }\end{array}$ & $89.5 \%$ & $90.25 \%$ & $92.0 \%$ & $90.5 \%$ \\
\hline $\begin{array}{c}\text { Percent of } \\
\text { participants that } \\
\text { made correct } \\
\text { decisions for 100\% of } \\
\text { vignettes }\end{array}$ & $\begin{array}{c}79.6 \% \\
(\mathrm{n}=160)\end{array}$ & $\begin{array}{c}69.9 \% \\
(\mathrm{n}=135)\end{array}$ & $\begin{array}{c}86.0 \% \\
(\mathrm{n}=172)\end{array}$ & $\begin{array}{c}47.1 \% \\
(\mathrm{n}=89)\end{array}$ \\
\hline
\end{tabular}

\section{DISCUSSION}

This is the first study to compare the ability of physical therapists to screen for medical referral in settings not exclusive to outpatient/private practice. In hypothetical vignettes covering a variety of conditions, participants made correct management decisions for $90 \%$ of vignettes. Identified appropriate management decisions were made for critical medical vignettes by $86 \%$ $(n=172)$ of participants. Practicing more than 23 years was predictive of correct management decisions in noncritical medical vignettes. Board certification and highest earned degree did not affect the management decisions.

Despite the weak logistic regression model, the results of this study suggest participants with more experience were more likely to make identified appropriate management decisions in noncritical vignettes compared to more recent graduates formally instructed in screening for medical referral in their entry level program. There has been an increased focus on screening for medical referral in entry-level curriculum. Additional research should be conducted to determine the types of learning experiences that have been effective for therapists related to screening for medical referral. Although not specifically addressed in our study, it is possible that many of the participants with more experience have taken additional coursework or specialized training to enhance their knowledge of screening for medical referral. Research has shown that physical therapists who have received additional training in screening for medical referral and practice in primary practice settings not only rated the importance of screening procedures more highly but also utilized those behaviors more often than those therapists who did not. ${ }^{17}$ Clark found that older, more experienced physical therapists not only had positive attitudes and beliefs toward screening for medical referral but felt it was important to patient/client management and outcomes. Almost all of the respondents in that study reported making a referral to another health care provider within the last 60 days. ${ }^{18}$ Future studies should examine the relationship of experience and clinical decision making skills related to medical screening.

A high percentage of participants in this study were able to recognize signs and symptoms that suggest DVT. In Vignette $6,86 \%$ $(n=172)$ of participants chose to refer and an additional $11.5 \%(n=23)$ chose treat/consult. Only $2.5 \%(n=5)$ chose not to refer. In contrast, another study found that for hypothetical high-risk patients, $25 \%$ of the participants who were members of the APTA's private practice section would not have referred at all. ${ }^{12}$ Our finding may be a result of enhanced awareness and educational efforts in recognition of signs of DVT, particularly in the literature and entry-level curricula. Much of the focus on screening in the literature has centered on outpatient musculoskeletal practice.9,12-15,17,19 There is, however, a need for research related to screening for referral in inpatient practice settings as well. Screening for medical referral was included in a recent practice analysis of acute care physical therapy. ${ }^{20}$ Clients in these practice settings are often medically unstable and present with multiple co-morbidities. Because of the close proximity of other health care professionals in these practice settings, physical therapists may not see their role in screening for referral. Of the 4 discarded vignettes in the Delphi Technique, 3 involved scenarios more commonly found in inpatient practice settings. There have been several studies that have discussed clinical decision-making and the importance of medical screening in acute care and other inpatient practice settings; however, there have been no studies performed to determine the frequency and accuracy of this process in practice..$^{20-23}$

Those in nonprimary care environments may not see the importance of screening for medical referral. Physical therapists practicing in a primary care setting more often included the identification and testing of signs and symptoms potentially arising

(C) The Internet Journal of Allied Health Sciences and Practice, 2016 
from visceral structures of the chest, abdomen and pelvis than those not practicing in primary care. Those that practiced in nonprimary care practice settings reported selecting and ordering imaging, identifying signs and symptoms of non-musculoskeletal conditions, and establishing a physical therapy diagnosis as less important when compared to physical therapists in primary care practice settings. ${ }^{19} \mathrm{It}$ is not known how many of the participants in this study practiced in primary care environments.

Board certification was not associated with correct management decisions in this study. Previous studies have shown that orthopedic certification or specific continuing education courses such as those provided by the military improve accuracy in medical screening in musculoskeletal conditions. ${ }^{9,19} \mathrm{It}$ is possible this effect was not seen in this study because the vignettes were not specific to outpatient practice settings and musculoskeletal conditions. While $18 \%(n=40)$ of participants in our study held board certification, the specific type of certification was not compared. Future research should investigate the relationship between the type of certification obtained and knowledge related to medical screening.

There were several limiting factors in this study. Use of vignettes precludes clinicians from performing a thorough history and examination. However, studies have shown that quality vignettes produce scores closer to the gold standard of standardized patients and are a valid and comprehensive method that directly focuses on the process of care provided in actual clinical practice. ${ }^{24}$ Vignettes can be used for diverse clinical practice settings, diseases and situations and in a published review vignettes were found to be appropriate to isolate decision-making abilities of physicians. ${ }^{25-27}$ Admittedly, the vignettes were brief; however, if longer, it is probable that the number of participants exiting the survey prior to completion would have been even higher than $20 \%(n=77)$.

It is probable that the participants who completed the survey were interested in screening for medical referral and the responses may not represent the majority of physical therapists or APTA members. The Delphi Technique was implemented to establish content validity, although only 2 vignettes reached $100 \%$ consensus by the expert panel. This suggests that even experts may find difficulty determining the most appropriate action regarding screening for medical referral. It is also possible that because the 8 vignettes used in this study were not specific to outpatient settings and musculoskeletal conditions or not in a military PT practice settings, it was more difficult to reach consensus on a correct management decision. Other methods of analyzing clinical decision making in medical screening that are not time consuming may be needed. ${ }^{26}$

The response rate was relatively low, so the sample size was smaller than anticipated. The email addresses were taken from a website, which may not have reliable or up-to-date information. The respondents were primarily from outpatient and private practice settings, which may have affected the results. It was difficult to match section membership with actual practice setting. Alternative sampling methods should be used in future studies. Because of low participant numbers, 2 variable categories, setting, and highest earned degree were collapsed in order to meet statistical assumptions. A larger study that encompasses all practice settings would be beneficial to compare these results. For traditional and non-critical medical vignettes, more than one answer was categorized as correct. The decision to accept more than one correct management decision for these vignettes were based on methodology in previous studies. ${ }^{13}$ Conservative management was not considered an incorrect response. However, in critical medical vignettes, only one response could be accepted because of the potential serious consequences of a lack of a referral. Further research is needed to determine the practice patterns and clinical decision-making process related to medical screening used by physical therapists in practice settings outside of outpatient/private practice. Exploring other methods of assessing the accuracy of screening for medical referral and factors affecting decision-making is also warranted. Educational opportunities to improve screening for medical referral can then be developed.

\section{CONCLUSION}

Despite the wide variety of vignettes presented, physical therapists in this study made identified appropriate management decisions for $90 \%$ of the vignettes. Physical therapists in all practice environments must screen for medical referral. It is imperative not only to ensure that the client is appropriate for physical therapy intervention, but it is also vital to recognize and identify signs and symptoms that warrant evaluation by other health care providers.

\section{REFERENCES}

1. Goodman CC, Snyder TK. Differential Diagnosis in Physical Therapy, 5e. St. Louis: Saunders; 2012.

2. Boissonnault WG. Primary Care for the Physical Therapist: Examination and Triage, 2e. St Louis: Elsevier; 2005.

3. The Guide to Physical Therapist Patient Client Management. Guide to Physical Therapist Practice 3.0. (internet) Alexandria, VA: American Physical Therapy Association; 2014. Available at: http://guidetoptpractice.apta.org/content/1/SEC1.body. Accessed May 15, 2015.

4. Evaluative Criteria for Accreditation of Physical Therapy Programs. (internet) The Commission on Accreditation in Physical Therapy Education. Alexandria, VA; 2014. Available at:

(C) The Internet Journal of Allied Health Sciences and Practice, 2016 
http://www.capteonline.org/uploadfiles/CAPTEorg/About_CAPTE/Resources/accreditation_Handbook/Evaluativecriteri a_PT.pdf Accessed October 20, 2014.

5. World Confederation for Physical Therapy. WCPT guideline for physical therapist professional entry level education. Internet London, UK: WCPT; 2011. Available at: http://www.wcpt.org Accessed May 15, 2015.

6. Portney LB, Watkins MP. Foundations of Clinical Research: Applications to Practice, 3e. Upper Saddle River: Prentice Hall Health; 2008.

7. Boissonnault WG, Ross MD. Physical therapists referring patients to physicians: A review of case reports and series. $J$ Orthop Sports Phys Ther. 2012;42(5):446-54. [PMID: 22282166]

8. Direct Access Utilization Survey. The American Physical Therapy Association. (internet) Alexandria, VA; available at: http://www.apta.org/DirectAccess/. Accessed May 18, 2015.

9. Murphy BP, Greathouse D, Matsui I. Primary care physical therapy practice models. J Orthop Sports Phys Ther. 2005 Nov;35(11):699-707. [PMID:16355912]

10. Childs JD, Whitman JM, Sizer PS, Pugia ML, Flynn TW, DeLitto A, et al. A description of physical therapists knowledge in managing musculoskeletal conditions. BMC Musculoskelet Disord. 2005;6:32. [PMID:15963232]

11. Haggman $S$, Maher $C G$, Refshauge KM. Screening for symptoms of depression by physical therapists managing low back pain. Phys Ther. 2004; 84(12):1157-66. [PMID:15563256]

12. Riddle DL, Hillner BE, Wells PS, Johnson RE, Hoffman HJ, Zuelzer WA. Diagnosis of lower extremity deep vein thrombosis in outpatients with musculoskeletal disorders: A national survey study of physical therapists. Phys Ther. 2004;84(8):717-28. [PMID:15283622]

13. Jette DU, Ardleigh K, Chandler K, McShea L. Decision making ability of physical therapists: physical therapy intervention and medical referral. Phys Ther. 2006 Dec;86(12):1619-29. [PMID:17138843]

14. Mechelli F, Preboski Z, Boissonnault WG. Differential diagnosis of a patient referred to physical therapy with low back pain: abdominal aortic aneurysm. J Orthop Sports Phys Ther. 2008 Sept;38(9):551-7. [PMID:18758044]

15. Walsh RM, Sadowski GE. Systemic disease mimicking musculoskeletal dysfunction: a case report involving referred shoulder pain. J Orthop Sports Phys Ther. 2001 Dec;31(12):696-701. [PMID:11767245]

16. Hasson F, Keeney S, McKenna H. Research guidelines for the Delphi survey. J Adv Nurs. 2000 Oct;32(4):1008-15. [PMID: 11095242]

17. Donato, EB, DuVall RE, Godges JJ, Zimmerman GJ, Greathouse DG. Practice Analysis: Defining the clinical Practice of Primary Contact Physical Therapy. J Orthop Sports Phys Ther. 2004 Jun;34(6):284-304. [PMID:15233391]

18. Clark DE. Screening for medical referral: Attitudes, beliefs, and behaviors of physical therapists with greater than 10 years experience. (dissertation). Birmingham (AL): University of Alabama Birmingham;2007.

19. Moore JH, Goss DL, Baxter RE, DeBerardino TM, Mansfield LT, Fellows DW, et al. Clinical diagnostic accuracy and magnetic resonance imaging of patients referred by physical therapists, orthopedic surgeons and non orthopedic providers. J Orthop Sports Phys Ther. 2005 Feb;35(2):67-71. [PMID:15773564]

20. Gorum SL, Hakim EW, Johnson W, Bose S, Harris KS, Crist MH, et al. Nationwide acute care physical therapist practice analysis identifies knowledge, skills and behaviors that reflect acute care practice. Phys Ther. Oct 2010;90(10):1453-67. [PMID: 20688876]

21. Masley PM, Havrilko CL, Mahnensmith MR, Auburt M, Jette DU. Physical therapist practice in the acute care setting: A Qualitative Study. Phys Ther. 2011 Jun;91(6):906-19. [PMID:21511991]

22. Smith M, Higgs J, Ellis E. Characteristics and processes of physiotherapy clinical decision-making: a study of acute care cardiorespiratory physiotherapy. Physiother Res Int. 2008 Nov;13(4):209-22. [PMID:18985624]

23. Wainwright SF, McGinnis PQ. Factors that influence the clinical decision-making of rehabilitation professionals in longterm care practice settings. J Allied Health. 2009 Fall;38(3):143-51. [PMID:19753425]

24. Peabody JW, Luck J, Glassman P, Dresselhaus TR, Lee M. Comparison of Vignettes, standardized patients, and chart abstraction. A prospective validation study of 3 methods for measuring quality. JAMA. 2000 April|283(13):1715-23. [PMID:10755498]

25. Peabody JW, Luck J, Glassman P, Jain S, Hansen J, Spell M, et al. Measuring the Quality of physician practice by using clinical vignettes: A prospective validation study. Ann Intern Med. Nov 2004;141(10):771-80. [PMID:15545677]

26. Saver BG, Taylor RT, Treadwell JR, Cole WG. Do physicians do as they say? The case of mammography. Arch Fam Med. 1997 Nov-Dec;6(6):543-8. [PMID:9371047]

27. Veloski J, Tai S, Evans AS, Nash DB. Clinical vignette based surveys: A tool for assessing physician practice variation. Am J Med Qual. 2005 May-Jun;20(3):151-7. [PMID:15951521] 


\begin{tabular}{|c|c|c|}
\hline \multicolumn{3}{|r|}{ APPENDIX } \\
\hline Type & Case & Description \\
\hline \multicolumn{3}{|l|}{ Traditional } \\
\hline & 5 & $\begin{array}{l}\text { A 79-year-old male with a history of coronary artery disease, chronic obstructive } \\
\text { pulmonary disease, chronic renal insufficiency and a right transfemoral } \\
\text { amputation is seen in physical therapy with balance and ambulation difficulty. } \\
\text { He has been ambulating with a rolling walker and a prosthesis for several years } \\
\text { but his wife reports that his activity level has declined significantly over the past } \\
\text { six months. He has had frequent falls and complains of mild shortness of breath } \\
\text { with activity. }\end{array}$ \\
\hline & 8 & $\begin{array}{l}\text { A 53-year-old woman with a fairly sedentary lifestyle complains of a recent } \\
\text { onset of deep, dull, aching pain in the posterior cervical and interscapular region } \\
\text { of her upper back. The pain began after she slipped off a curb and nearly fell. } \\
\text { She has tenderness in her upper trapezius muscle and she states she has pain } \\
\text { when raising her arm and turning her head. Pain is intermittent and is relieved } \\
\text { when she lies down. She demonstrates no motor or sensory loss. }\end{array}$ \\
\hline \multicolumn{3}{|r|}{ (2) } \\
\hline & 2 & $\begin{array}{l}\text { A 40-year-old female with a history of spina bifida who lives alone is referred to } \\
\text { home health physical therapy for treatment of a sacral wound following an acute } \\
\text { care stay. The physician has continued the intravenous antibiotics. She reports } \\
\text { severe pain with sitting and is having difficulty with transfers. Her wound has } \\
\text { moderate serosanguinous drainage, a strong odor and yellow exudate. }\end{array}$ \\
\hline & 9 & $\begin{array}{l}\text { A 43-year-old female is seeking physical therapy for non-operative treatment of } \\
\text { a right shoulder rotator cuff tear that occurred after a recent fall. She complains } \\
\text { of pain during right shoulder elevation and an inability to lift her arm over her } \\
\text { head. While reviewing her medical history, she mentions the development of a } \\
\text { cough over the past few days along with a low-grade fever. She is being treated } \\
\text { for melanoma that was diagnosed } 4 \text { months ago in the right cervical lymph } \\
\text { nodes and has been receiving bio chemotherapy for the past } 3 \text { months. }\end{array}$ \\
\hline & 10 & $\begin{array}{l}\text { A } 46 \text {-year-old female with a history of irritable bowel syndrome and ovarian } \\
\text { cysts complains of low back pain. It has bothered her on and off for about one } \\
\text { year for no apparent reason. The low back pain varies and worsens with lifting } \\
\text { and prolonged standing. It is intermittent, does not radiate and is relieved with } \\
\text { rest. She mentions that she has had pain, occasional bloating and a sense of } \\
\text { heaviness in the pelvic/ abdominal region for the past few months. }\end{array}$ \\
\hline & 11 & $\begin{array}{l}\text { A } 75 \text {-year-old female was referred to home health physical therapy following an } \\
\text { open reduction internal fixation of the left ankle from a fall five days ago. She is } \\
\text { non-weight bearing but is able to transfer in and out of a wheelchair } \\
\text { independently and propel it short distances. She complains of a chronic non- } \\
\text { productive cough over the past several years that seems to be worsening and a } \\
\text { recent onset of increased shortness of breath since her injury. She notes that } \\
\text { she has taken several types of medications during the past year due to } \\
\text { repeated respiratory tract infections. }\end{array}$ \\
\hline \multicolumn{3}{|l|}{ Critical Medical } \\
\hline & 6 & $\begin{array}{l}\text { An 18-year-old male suffered an incomplete C6 spinal cord injury due to MVA. } \\
\text { The patient was treated in the hospital for } 2 \text { months and once stabilized was } \\
\text { transferred to a rehabilitation facility. He has been in the facility for several } \\
\text { weeks. During his am therapy session, you notice unilateral swelling ( } 1 \text { inch } \\
\text { greater than right) and warmth of his left lower extremity. The swelling did not } \\
\text { improve with elevation. }\end{array}$ \\
\hline & 7 & $\begin{array}{l}\text { An } 80 \text { - year-old active but frail woman fell on a rug in her apartment and landed } \\
\text { on her outstretched hands. She complains of tenderness over the lateral aspect } \\
\text { of the right wrist and distal forearm, and a bony deformity is palpable. Her wrist } \\
\text { is swollen and painful, with decreased range of motion. }\end{array}$ \\
\hline
\end{tabular}

(c) The Internet Journal of Allied Health Sciences and Practice, 2016 